\title{
Assessment of Knowledge on Baby-friendly Hospital Initiative among Staff Nurses in MCH Unit at MGMCRI, Puducherry, India
}

\author{
Surendran Raju ${ }^{1}$, Priyalatha Ganesh ${ }^{2}$, Rajeswari Subbarayan ${ }^{3}$
}

\begin{abstract}
Background: Breast milk is the perfect food for a normal neonate. It is the best gift a mother can give to her baby. It contains all the nutrients for the normal growth and development for the baby from the time of birth to the first 6 months of life. It is necessary to timely evaluate knowledge and to bring about positive attitude in the staffs regarding the implementation of the baby-friendly hospital initiative policy. To assess the knowledge on baby-friendly hospital initiative policy (BFHI) among staff nurses in the MCH unit at MGMCRI\&H, Puducherry.

Materials and methods: Quantitative research approach, non-experimental descriptive design. The population for the study consisted of 60 staff nurses from the maternal and childcare unit of MGMCRI, Puducherry. The data were collected through a structured questionnaire to assess the knowledge of staff nurses on the BFHI. The data were analyzed both descriptive (mean, frequency, percentage and standard deviation) and inferential statistics (Kruskal-Wallis)

Results: Discussion on the findings was arranged based on the objectives of the study. The present study reveals that, among 60 staff nurses, $48(80 \%)$ of them had moderately adequate knowledge, $9(15 \%)$ of them had adequate knowledge and $3(5 \%)$ of them had inadequate knowledge regarding BFHI policy.

Conclusion: The study reveals that most of the staff nurses had moderately adequate knowledge of the BFHI policy.

Keywords: BHFI policy, Knowledge, Staff nurse.

Pondicherry Journal of Nursing (2019): 10.5005/jp-journals-10084-12108
\end{abstract}

\section{INTRODUCTION}

Breastfeeding is a natural way of feeding the infant with milk from the mother's breast. ${ }^{1,2}$ It is a living fluid and contains exactly the adequate amount of nutrients required by a baby, in the appropriate proportions, to make sure that the baby gets the perfect balanced meal through enriched breast milk. ${ }^{3-7}$ No other manufactured milk, no matter how fortified it is, comes even close to being as nutritious as breast milk. ${ }^{8,9}$ The social change brought about by the nuclear family has forced many people to ask whether our practices, recommendations, prejudices, commensurate with the scientific reality. ${ }^{10-12}$ With this background, the world alliance for breastfeeding promotion has started appropriately the program Baby-friendly Hospital Initiative to protect, promote, and encourage exclusive breastfeeding in all hospitals. ${ }^{13}$

Recognizing and considering the vital role of nurses as health promoters and patient advocates, and their position as the largest group of healthcare workers in the hospitals, World Health Organization and United Nations International Child Emergency Fund are asking nurses to facilitate the implementation of BFHI in their hospital. ${ }^{14-16}$ Hence nurses play a vital role in the implementation of the same in all the hospitals. ${ }^{17,18}$

The benefits of breastfeeding are more tremendous ${ }^{19-21}$ and the following benefits in BFHI hospitals are obvious, immediate and substantial; ${ }^{22,23}$ decreases infection rate, ${ }^{24,25}$ improves survival of low birth weight infants. ${ }^{22-24}$ Reduction in nursing load as rooming in and demand feeding make nursery care easier. ${ }^{26-28}$ Hence it is required to timely evaluate knowledge and to bring about positive attitude in the staff nurses regarding the implementation of 10 steps of BFHI policy in their respective
${ }^{1-3}$ Department of Medical Surgical Nursing and Department of Child Health Nursing, Kasturba Gandhi Nursing College, Sri Balaji Vidyapeeth, Puducherry, India

Corresponding Author: Surendran Raju, Department of Medical Surgical Nursing and Department of Child Health Nursing, Kasturba Gandhi Nursing College, Sri Balaji Vidyapeeth, Puducherry, India, Phone: +91 822022464, e-mail: radjou.surensr@gmail.com

How to cite this article: Raju S, Ganesh P, Subbarayan R. Assessment of Knowledge on Baby-friendly Hospital Initiative among Staff Nurses in MCH Unit at MGMCRI, Puducherry, India. Pon J Nurs 2019;12(1):8-10.

Source of support: Nil

Conflict of interest: None

hospitals and thus contribute to the reduction of infant morbidity and mortality. ${ }^{28,29}$

Investigators personal experience from day-to-day staff nurse's practices in hospitals, though nurses play a vital role in motivating and supporting mothers regarding breastfeeding, many hospitals in India still are lagging behind in implementing the BFHI policy ${ }^{28}$ either due to insufficient manpower, excessive tasks and more workload performed by nurses, lack of continuity in the teamwork, out-of-context guidelines, less commitment with proposal, lack of continuing nursing education program, for the staffs regarding this policy. ${ }^{30-34}$ They do not find time to educate mothers regarding BFHI policy. ${ }^{35-39}$ Hence it is needed to timely evaluate knowledge and to bring about positive attitude in the staffs regarding the implementation of 10 steps of BFHI policy in their hospitals and thus contribute in the reduction of infant mortality and morbidity. ${ }^{40-45}$ 


\section{Objectives}

- To assess the knowledge on BFHI policy among staff nurses in the $\mathrm{MCH}$ unit at MGMCRIH, Puducherry.

- To find the association between knowledge on BFHI policy among staff nurses with selected demographic variables.

\section{Materials and Methods}

Quantitative research approach was used for this study. The research design used for the study was non-experimental descriptive design. This study was conducted in Mahatma Gandhi Medical College and Research Institute, Puducherry. The population for the study consisted of 60 staff nurses from the maternal and childcare unit of MGMCRI, Puducherry. The data were collected through a structured questionnaire consists of 2 parts-part 1 consists of interview schedule to assess the demographic data such as age, gender, educational status, working area, experience, previous knowledge and part 2 structured questionnaire on BFHI policy which contains 30 questions to assess the knowledge of staff nurses on BFHI. The data were analyzed both descriptive (mean, frequency, percentage and standard deviation) and inferential statistics (Kruskal-Wallis).

\section{Results}

Table 1 shows the distribution of the level of knowledge on BFHI policy among staff nurses. Among 60 staff nurses, $48(80 \%)$ of them had moderately adequate knowledge, $9(15 \%)$ of them had adequate knowledge and $3(5 \%)$ of them had inadequate knowledge.

The data also revealed that educational status and previous knowledge has a significant association with the level of knowledge. The obtained test value was 2.170 and 7.12 , respectively. It was significant at $p<0.05$ level and thus there was a significant association between educational status and previous knowledge. Other variables were not significant.

\section{Conclusion}

The study revealed that most of the staff nurses had moderately adequate knowledge of the BFHI policy. It can be inferred that most of the staff nurses had adequate knowledge of the BFHI policy. The findings of the study can be utilized for conducting further research in bringing any innovation in BFHI. ${ }^{49,51}$

\section{Recommendations}

- The research study can be replicated on a larger population drawn from different hospitals of Puducherry.

- A study on the effectiveness of BFHI on breastfeeding and infant mortality reduction can be done.

Table 1: Assessment of level of knowledge on BFHI policy among staff nurses

\begin{tabular}{lcc}
\hline Level of knowledge & No. of subjects $(n)$ & Percentage \\
\hline Adequate knowledge & 9 & 15 \\
Moderately adequate & 48 & 80 \\
knowledge & & \\
Inadequate knowledge & 3 & 5 \\
Total & 60 & 100 \\
\hline
\end{tabular}

- A study can be done on the antenatal mothers to assess their knowledge attitude and practice of BFHI.

\section{Decleration of Patient Consent}

The authors certify that they have obtained all appropriate patient consent forms. In the form of patient(s) has/have given his or her their consent for his/her/their images and other clinical information to be reported in the journal. The patients understand that their names and initials will be published and due efforts will be made to conceal their identity, but anonymity cannot be guaranteed.

\section{References}

1. Ghai OP. Essential of Pediatrics, 6th ed., New Delhi: Dr. O.P. Ghai Publications; 2005. p. 296.

2. Cramton R, Zain-Ul-Abideen M, Whalen B. Optimizing successful breastfeeding in the newborn. Curr Opin Pediatr 2009;21(3):386-396. DOI: 10.1097/MOP.0b013e32832b325a.

3. World Cancer Research Fund (PDF). UK Baby Friendly Initiative. UNICEF. 2007. Retrieved 2013-09-01.

4. World Health Organization. 10 facts on breastfeeding, accessed 20 April 2011.

5. Schwarz EB, Ray RM, Stuebe AM, Allison MA, Ness RB, Freiberg MS, et al. Duration of lactation and risk factors for maternal cardiovascular disease. Obstet Gynecol 2009 May;113(5):974-982. DOI: 10.1097/01. AOG.0000346884.67796.ca.

6. Bartick MC, Stuebe AM, Schwarz EB, Luongo C, Reinhold AG, Foster EM. Cost analysis of maternal disease associated with suboptimal breastfeeding. Obstet Gynecol 2013 Jul;122(1):111-119. DOI: 10.1097/AOG.0b013e318297a047.

7. Parul D. Pediatric Nursing, 2nd ed., New Delhi: Jaypee Publishers; 2007. pp. 24-51.

8. Technical Document: Public Health Accountability Agreement Indicators 2011-13 Ministry of Health and Long-Term Care Public Health Division Health Promotion Division "Archived copy" (PDF). Archived from the original (PDF) on 2014-02-03.

9. Breastfeeding Committee for Canada. BFl in Canada. Archived 201112-05 at the Wayback Machine. Accessed 2 August 2011.

10. WHO. Country Profile: Atlas, Geneva. (serial online) 2006 Mar;117: 380-386.

11. Jones F, Green M. Baby friendly care. Can Nurse 1993;89(9):36-39.

12. Cramton R, Zain-Ul-Abideen M, Whalen B. Optimizing successful breastfeeding in the newborn. Curr Opin Peditr 2009 Jun;21(3): 386-396. DOI: 10.1097/MOP.0b013e32832b325a.

13. Gupta A, Mathur GP, et al. Policy on breastfeeding training of doctors and nurses in Breastfeeding and lactation management. Breastfeeding Promotion Network of India (BPNI) available from bpni@bpni.org, Website: www.bpni.org.

14. Sial IP. Redefining infant care the Baby-Friendly Hospital Initiative. Health Millions 1999 Jul-Aug;25(4):38-39.

15. Dabritz HA, Hinton BG, Babb J. Evaluation of lactation support in the workplace or school environment on 6-month breastfeeding outcomes. J Hum Lact 2009 May;25(2):182-193. DOI: 10.1177/ 0890334408328222.

16. Caldeira AP, Gonçalves E. Assessment of the impact of implementing the Baby-Friendly Hospital Initiative. J Pediatr (Rio J) 2007 Mar-Apr; 83(2):127-132. DOI: 10.2223/JPED.1596.

17. Rivera-Lugo M, Parrilla-Rodríguez AM, Dávila-Torres RR, Albizu-García C, Rios-Motta R. Full breastfeeding during the postpartum hospitalization and mothers' report regarding baby friendly practices. Breastfeed Med 2007 Mar;2(1):19-26. DOI: 10.1089/ bfm.2006.0025.

18. Bartick M, Stuebe A, Shealy KR, Walker M, Grummer-Strawn LM. Closing the quality gap: promoting evidence-based breastfeeding care in the hospital. Pediatrics 2009 Oct;124(4):e793-e802. DOI: 10.1542/peds.2009-0430. 
19. Sarasua I, Clausen C, Frunchak V. Mothers' experiences with breastfeeding management and support: a quality improvement study. Breastfeed Rev 2009 Mar;17(1):19-27.

20. Mothers and Children Benefit from Breastfeeding. Womenshealth. gov. 27 February 2009. Archived from the original on 16 March 2009.

21. UNICEF. The Baby-Friendly Hospital Initiative. Accessed 4 August 2011.

22. Jang GJ, Kim SH, et al. Effect of postpartum breast-feeding support by nurse on the breast-feeding prevalence. Taehan Kanho Hakhoe Chi 2008 Feb;38(1):172-179.

23. Bulhosa MS, Lunardi VL, Lunardi Filho WD, Gonçales SA. Promotion of breastfeeding by the nursing staff of a children-friendly hospital. Rev Gaucha Enferm 2007 Mar;28(1):89-97.

24. World Health Organization. Baby-friendly Hospital Initiative. Accessed 4 August 2011.

25. UNICEF. Innocenti Declaration on the Protection, Promotion and Support of Breastfeeding. Adopted at the WHO/UNICEF meeting on Breastfeeding in the 1990s: A Global Initiative, held at the Spedale degli Innocenti, Florence, Italy, 30 July-1 August 1990.

26. Breastfeeding and Maternal and Infant Health Outcomes in Developed Countries. Agency for Healthcare Research \& Quality. 2012-12-06. Retrieved 2013-09-01.

27. Greer FR, Sicherer SH, Burks AW. Effects of Early Nutritional Interventions on the Development of Atopic Disease in Infants and Children: The Role of Maternal Dietary Restriction, Breastfeeding, Timing of Introduction of Complementary Foods, and Hydrolyzed Formulas. Pediatrics 2008 Jan;121(1):183-191. DOI: 10.1542/ peds.2007-3022.

28. Ogbuanu IU, Karmaus W, Arshad SH, Kurukulaaratchy RJ, Ewart S. The effect of breastfeeding duration on lung function at age 10 years: a prospective birth cohort study. Thorax 2008 Nov;64(1):62-66. DOI: 10.1136/thx.2008.101543.

29. Mahr TA. Effect of Breastfeeding on Lung Function in Childhood and Modulation by Maternal Asthma and Atopy. Pediatrics 2008 Nov;122(9):S176-S177. DOI: 10.1542/peds.2008-2139H.

30. New Brunswick Department of Health. New Brunswick Provincial Report of the Baby-Friendly Self-Assessment Survey. [permanent dead link] March 2008.
31. B. C. Women's Hospital recognized as 'baby-friendly'. Archived from the original on 2019-04-12.

32. The Gender Dimension of the MDGs in R. O. C. (Taiwan).

33. Raman TR, Parimala $V$, lyengar $A$. Baby friendly hospital initiative experiences from a service hospital. Med J Armed Forces India 2001 Jan;57(1):23-25. DOI: 10.1016/S0377-1237(01)80084-8.

34. Gupta S. Textbook of Pediatrics, 11th ed., New Delhi: Jaypee Brothers Publications; 2012. p. 80.

35. Hofvander Y. Breastfeeding and the Baby Friendly Hospitals Initiative (BFHI): Organization, response and outcome in Sweden and other countries. Acta Paediatr 2005 Aug;94(8):1012-1016. DOI: 10.1111/j.1651-2227.2005.tb02038.x.

36. About Baby Friendly: All about us: History of Baby Friendly in the UK. UNICEF UK. Archived from the original on 12 September 2014.

37. Montgomery DL, Splett PL. Economic Benefit of Breast-Feeding Infants Enrolled in WIC. J Am Diet Assoc 1997 Apr;97(4):379-385. DOI: 10.1016/s0002-8223(97)00094-1.

38. Green M, Jones F. Baby friendly care. Can Nurse 1993;89(9): 36-39.

39. Center for Disease Control and Prevention (2013). Strategies to Prevent Obesity and Other Chronic Diseases: The CDC Guide to Strategies to Support Breastfeeding Mothers and Babies (PDF). US Department of Health and Human Services.

40. NW, 1615 L. St, et al. The Social Life of Health Information | Pew Research Center. 11 June 2009, https://www.pewinternet. org/2009/06/11/the-social-life-of-health-information/.

41. WHO|Breastfeeding education for increased breastfeeding duration. www.who.int. Retrieved 2017-11-27.

42. Bass JL, Gartley T, Kleinman R. Unintended Consequences of Current Breastfeeding Initiatives. JAMA Pediatr 2016 Oct 1;170(10):923-924. DOI: 10.1001/jamapediatrics.2016.1529.

43. Feeding in exceptionally difficult circumstances. World Health Organisation.

44. Ubelacker, Sheryl (1 April 2013). Push on for more baby-friendly hospitals, support for breastfeeding key component. Globe and Mail. Retrieved 21 March 2018.

45. Rosenberg KD, Stull JD, Adler MR, Kasehagen LJ, Crivelli-Kovach A. Impact of hospital policies on breastfeeding outcomes. Breastfeed Med 2008 Jun;3(2):110-116. DOI: 10.1089/bfm.2007.0039. 